septicæmia, in the sense that the causal organism multiplies mainly in the blood, but this organism, apparently, can also multiply in extravascular positions, and the transparent character of the exudates which are formed in the course of the disease may be explained by supposing that the bacterium of horse-sickness exerts a negative chemiotaxis with regard to the leucocytes.

In animals dead of horse-sickness the liver is generally very full of blood, and this hepatic congestion is probably in large measure determined by the congestion and odema of the lungs. In one instance small multiple areas of necrosis were present in the parenchyma of the liver (Experiment III.), but it is probable that these had no connection with the disease. Negative characters of much importance are the normal appearance of the mesenteric and other groups of lymphatic glands, and the absence of much enlargement or softening of the spleen. These characters alone would enable one to distinguish between horse-sickness and anthrax at the post-mortem examination in most if not all cases, without having recourse to microscopic examination. Another conspicuous difference between these two diseases is furnished by the condition of the blood. As is well known, the blood of animals dead of anthrax remains semi-fluid, or at most forms only a very soft clot, whereas in horse-sickness the blood furnishes a clot of quite normal firmness.

Horse-sickness appears to be a septicæmia in the further sense that death is due to the toxic effects of substances manufactured by the bacteria multiplying in the blood. No doubt in those cases in which there is very extensive pulmonary œdema, interference with the reration of the blood will act as a contributory cause of death, or it may even be the final cause; but in a considerable number of the experiments recorded in this article the combined structural lesions, such as the cedema of the lungs and the exudation into the pleural and pericardial sacs, were not sufficient to account for the fatal issue. It ought also to be noticed that the microbe of horse-sickness does not appear to attach itself to the red corpuscles of the blood; at least that seems to be indicated by the fact that these corpuscles appear quite normal in preparations made from the blood, and by the normal tint of the serum furnished by horse-sickness blood.

\title{
SUB-ACUTE OBSTRUCTIVE INTESTINAL COLIC OF THE HORSE.
}

WITH SPECIAL REFERENCE TO ITS ETIOLOGY IN THE DISTRICT OF SOUTH LINCOLNSHIRE, INCLUDING A REPORT ON EIGHTEEN CONSECUTIVE CASES, AND AN ARGUMENTATIVE DISCUSSION ON ITS TREATMENT. ${ }^{1}$

By H. Caulton Reeks, F.R.C.V.S., Spalding.

"Colic" in the horse has for a long time served to designate innumerable and widely differing diseases, whose only point in common

\footnotetext{
I The writer feels it incumbent on him to offer a word of apology for the apparently lengthy title that heads the article. Nevertheless, he thinks it will be seen that no other description would fully cover the ground that has been traversed in its preparation.
} 
has been the evidence of abdominal pain. The term must necessarily be most vague when it attempts to offer any explanation of a particular case in which the symptoms are most largely those of pain in the abdomen. If we use the word in its most restricted sense, it should mean only pain in the bowels, or enteralgia. This is a nervous sensibility in the region of the plexus mesentericus, and, as such, is not often observed in our cases. In the widest possible acceptation of the term, colic will indicate - apart from this enteralgia-all painful affections of the intestines that are not consequent upon inflammation or textural disease of the bowel walls.

The human surgeon, by clear and incisive reasoning deduced from the symptoms observed by himself and the help afforded him by his patient, has the power of making such subtle distinctions in different varieties of colic as to render his skill in diagnosis an object of admiration to the veterinarian. The disadvantages the veterinary surgeon labours under in trying to attain even a modicum of the medical man's skill in this respect are many, but they will only be too evident on the conclusion of this article, and render further reference here unnecessary. It is quite plain, however, that our first duty should be to draw up and tabulate, as far as possible, the different morbid conditions that may give rise to colic, using the word in its widest sense. This has already been done for us by that eminent and conscientious clinical observer, Professor Friedberger, of Munich. In Professor Friedberger's pamphlet, Die Kolik der Pferde, Sechs Klinische Vorträge, this table is given as follows:-

I. True Colic, proceeding from the intestinal canal.

2. False Colic, arising from a diseased state of the abdominal organs. (Under this heading will come especially affections of the bladder and sexual organs, which give rise in the first instance to similar external evidences of suffering.)

True Colic is then taken, and subdivided in the following manner :A.-Essential, to which may be referred the under-mentioned causes:-

I. Colic without material cause, as the so-called nervous cramp (or rheumatic colic).

2. Colic consequent upon anomalies of the intestinal contents. Such are-

(a) Colic produced by over-feeding.

(b) Colic brought on by flatulence (wind colic).

(c) The colic occasioned by stoppages in the intestinal canal. These obstructions may arise from fæcal accumulations, stones, concretions, etc.

B.-Symptomatic. Such are--

(a) The colic produced by worms.

(b) The colic resulting from poisons.

(c) Colic brought on by structural disease and changes in the relative position of the intestines; colic occasioned by acute catarrh and croup affecting the delicate mucous membrane of the colon; colic from carbuncular formations on the mucous membrane; colic from dysentery, and from the so-called internal cramp; colic from wounds of the stomach and entrails; and colic from spontaneous laceration or perforation of those organs. 
(d) Colic resulting from morbid conditions of the abdomen, and the covering of the intestines (peritoneum).

A mere perusal of this extensive and complete classification of the varieties of colic will serve to impress upon us the absolute necessity of looking for much more than the mere exhibition of pain on the part of our patients in order to arrive at a diagnosis that will approach with any degree of accuracy to the truth.

Now to commence the description of that special form of colic this paper is dealing with, namely, obstructive intestinal colic of a subacute type. A reference to Professor Friedberger's table shows plainly enough that it comes under the second division of the Essential form of True Colic-i.e., colic consequent upon anomalies of the intestinal contents. The question then arises, Will it be $(a)$ the colic produced by over-feeding, or $(c)$ the colic occasioned by stoppage in the intestinal canal? In my opinion these two forms of colic are to a very great extent interchangeable; for in the colic I am about to describe (that occasioned by stoppage in the intestinal canal, known also commonly as impaction of the intestines) there can be no doubt whatever that over-feeding is responsible for a great majority of the cases. That is the case, at any rate, in South Lincolnshire. There may or may not be colic with over-feeding, and yet the over-charging of the horse's intestines may give rise to impaction, or stoppage-facal accumulation. To make myself plainer still-we may have over-feeding and yet no symptom of colic until it has become really a case of impaction or stoppage. That is really what always occurs in the great majority of cases in the district I have under consideration, the only premonitory symptoms (prior to impaction or stoppage) being dulness. No exhibition of abdominal pain whatever.

Then, again, take $(b)$, or the colic brought on by flatulence. Here also, it is evident that it may arise merely as a result either of overfeeding or of obstruction. So that, to sum up, we may say, The $(a)$ form of colic, viz., that produced by over-feeding, may or may not be accompanied by flatulence, and may or may not be productive of obstruction, again with or without flatulence. That is what one really sees if notes are taken of a series of cases, and I will endeavour to make my statement still clearer directly. I do not wish to infer that there is no such thing as a pure type of flatulent colic. I merely wish to point out that in a great many cases the flatulence is solely dependent on previous conditions that are in themselves another and distinct form of the disease.

\section{PREDISPOSING CAUSES.}

Foremost among these come several conditions in the horse, which, though quite normal in themselves, are nevertheless entirely favourable to the production of this disorder. Firstly, the small size of the animal's stomach and the great length of his intestines must be borne in mind. Then, with regard to the stomach itself, it is an anatomical fact, as a careful dissection shows, that its very build is a distinct bar to the act of vomition. Consequently, no matter how sick the animal may feel, nor what deleterous matter he may have swallowed, there it must remain, or travel the 
whole length of the sensitive and absorbent surfaces of the intestines before gaining exit from the body. The anatomical facts that lead one to that statement are as follows:-

First.-The small size of the stomach, and its want of contact with the abdominal walls; this is a distinct hindrance to its compression.

Second.-The narrowness of the oesophageal opening, together with the arrangement of the cardiac fibres; these being two factors in the formation of a complete occlusion of the opening.

Third.-There is the almost cæcal character of the duodenal end of the organ.

Proceeding, then, to the intestines, we note first the pressure of the so-called duodenal trap, and I cannot help but think that this must be another great factor in the production of cases of obstruction. Following this, we observe the difference in the size of the lumen of the colon itself, together with its several flexures, and note also the length and comparatively free location of this organ and the cæcum. Taken collectively, these are all circumstances quite normal in themselves, which must still be held to be favourable to the production of colic, and particularly that form of colic we are describing. Undoubtedly, also, age must be put down as a predisposing cause of this complaint. With advancing age, there is not the amount of what is commonly called "tone" in the system. The digestion is far from being so good and so quick, and a large amount of bulky food is less easily disposed of. The circulation not being so free, there is less gastric juice secreted-oftentimes not sufficient-and impaction is the result. The teeth do not perform their proper function, and the food is passed on in a half-masticated form, and without its allimportant and requisite admixture of salivary fluid. Here, also, attention may be given to the time occupied in the passage of food through the digestive organs of the horse.

Henry Jarvis, in 1872 , in four experiments, observed the following :-

Horse No. I.-Fed on oats, performed 9 mile journey, and passed oats in twenty-two hours.

Horse No. 2.-Fed on oats, performed half-an-hour's exercise, and passed oats in twenty-four hours.

Horse No. 3.-Fed on oats, kept quiet in stable, and passed oats in twenty-seven hours.

Horse No. 4.-Fed on oats, kept quiet in stable, and passed oats in twenty-seven and a half hours.

This, I need scarcely add, is a comparatively short time, and the healthy animal passes on an average twelve motions daily. In fact, it is no exaggeration to say that the cessation of the normal act of defacation for twelve hours, or even less, is quite sufficient to bring on symptoms of pain, except under extraordinary circumstances.

Hereditary Predisposition.--Are diseases of the bowels hereditary? Why not? May there not be a diathesis transmitted, by which the structure of the bowels is more susceptible to disease in some than in others? If cases were carefully traced back, might we not find that the sire or the dam had been subject to some disease of the bowels or other?

These are the questions asked by a practitioner in the Veterinary 
Journal. To all of them I can confidently answer in the affirmative. I have frequently been told, when attending a case, that the animal's mother was always colicked. "Aye, and her mother died from it too!" is often the close of the owner's remarks. Seeing that from 50 to as many as 90 per cent. of the total cases in some practices are those of colic, it cannot be much of an argument, I admit, to say that because one animal's mother died from colic the off-spring must necessarily inherit a fatal predisposition. Nevertheless, the point that has struck me is the frequency with which one hears the word alway's inserted.

Temperament as a Predisposing Fiactor.-That really comes under the heading of heredity, and all I need add is that I have frequently noticed that animals of a sluggish lymphatic nature are more liable to this special form of colic than are any other. Last, but by no means least, in this lengthy category of predisposing causes comes a reference to the mucous membrane of the intestines. I do not think that anyone will deny that the delicate lining of the bowels in the horse is exceedingly more sensitive to all deleterious influences than in any other animal we have to deal with. As a proof of that, witness the agonising pains that accompany the least disturbance of his alimentary tract, and the rapidity with which the animal succumbs. Witness, also, the rapid and fatal effect of comparatively small doses of irritant poisons, the animal's dejected and downcast demeanour, and his absolute indifference to all other circumstances than the pain which is killing him, rendering his case hopeless and pitiable in the extreme.

\section{EXCITING CAUSES.}

Foremost among the many actual causes of this complaint must come the one which I can best describe by calling it "civilisation." The horse, probably more than any other animal, is under man's control and at man's disposal; and often such men! In South Lincolnshire, at any rate, they are not men, but lads; lads of from eighteen to twenty, and ignorant and obstinate at that. They are distinctly outside the sphere of the farmer's influence, owing largely to the growing scarcity of agricultural labour, and they have practically carte-blanche to do exactly as they please with the animals under their care; for one disapproving word from the owner and master is sufficient to at once cause this man to send in his notice. He knows full well he will easily obtain work elsewhere, and, prompted as much by spite as an inbred hatred of the class, leaves his master in the lurch. It is to such men that whole studs of valuable animals (entires and brood shire mares) are entrusted; not from choice, but necessity. Can one wonder, then, that mistakes occur in the animal's dietary? Unless supplied with an overwhelming abundance of fattening food, and every chance to steal more, these men literally strike. The result is that the farmer gives way, and the animals grow into walking exhibitions that would put a Smithfield prize ox to shame.

This is no exaggerated picture I am drawing, as I am simply stating facts; and it is necessary that I should enlarge somewhat on the .customs and method of feeding here in Lincolnshire, in order to pave the way for the treatment to be described at the end of this article. 
One of the greatest errors in the dietary, and one which I am continually fighting against, is the absolute dread these men have of giving the animals water to drink. I have repeatedly walked into a stable in the afternoon of a hot blazing summer's day, and seen a row of horses just returned from their work in the fields. Hard at it they have been from 7 o'clock in the morning until 3 in the afternoon, and as a preliminary to their feeding they are given $d r y$ wheat chaff to eat, while the "man" has gone to get his dinner. Even then, poor brutes, they have their usual feed to get through on the man's return from dinner before a drop of water passes their lips.

Put all these facts together-long hours of abstinence, 7 till 3 ; weather at summer's highest temperature; work hard; no water; the climax-dry food before drink. Need we wonder, then, at cases of obstruction? I feel as though I were enlarging more upon this than I should do in a scientific paper, but 'tis a poor science that takes not into consideration the every-day facts surrounding it. In this district, then, the causes of colic brought about by civilising the horse, to sum them up concisely, are primarily the errors in diet.

Food.-I look upon food as being a prominent factor in the causation of colic in this district for two reasons. Firstly, in nine cases out of ten the food is selected without any regard for the proper balance of constituents as a suitable, easily digested, and economical diet. Secondly, far too great a quantity is used. More than enough is allowed the men by the owners, but they invariably steal more. I attempted, for the purposes of this paper, to obtain the quantities per horse, per diem, measured out in some of the stables. This I found to be quite impossible, the farmer telling me one thing, the men another, and the horse contradicting them both. Oats, the food par excellence for the horse, is very seldom used. It is sent in the bulk to market, and maize purchased in its stead. With the maize the owner gives whatsoever else may by chance be on the farm. This more often than not is wheat or barley - two notoriously bad foods for horses. If wheat or barley be not available, then bran is the next obtained. Bran mixed with maize forms much too laxative a diet for the horse in work; it is certainly not economical, and it is, moreover, a frequent cause of an attack of colic. It is also a common practice, when making horses up for sale, to diet them largely on food that has been boiled. Though probably more easy of digestion, I fear it is often ravenously bolted, and in that way lays the foundation stone for a lasting edifice of colic. When to these few remarks I add that the animals are fed at improper times, and repeat that it is extremely difficult, if not altogether impossible, to find cases where the food is properly measured and weighed out to each horse, it will be seen that the question of feeding is not one to be lightly overlooked when dealing with cases of obstruction.

Water.-For the remarks and tables of analyses under this heading I am indebted to my friend, Mr E. Wightman Bell, F.C.S., author of "Manures-their Sources, Composition, and Application."

"Almost without exception, the water supplied to horses and cattle in the district of South Holland, Lincolnshire, is either surface water or stored rain water. The surface water is derived either from shallow wells, or from some of the innumerable so-called drains, which have been formed for the purpose of carrying off the excess of water from 
the fen district, and finally discharging the same into the tidal rivers which empty into The Wash. These drains are not tidal, nor do they, except by accident, receive any salt water; a small amount of sewage matter is discharged into them, but this quantity is very small, as the districts through which they pass are very thinly populated. When, however, we consider that the land which these water-courses drain, and in which the shallow wells are sunk ${ }^{1}$ is mostly arable, very heavily manured, we may expect to find the water contain a rather large amount of organic matter. Geological and geographical conditions are responsible for the enormous amount of chlorine present in these surface waters; geological, because the soil has been for the most part covered by salt water at some time, and geographical on account of sea-spray being carried inland on a good breeze, and so affecting the composition of the rain-water as it reaches the collecting area."

\section{Shallow Well Water-Analysis of Three Typical Samples, in Parts per 100,000.}

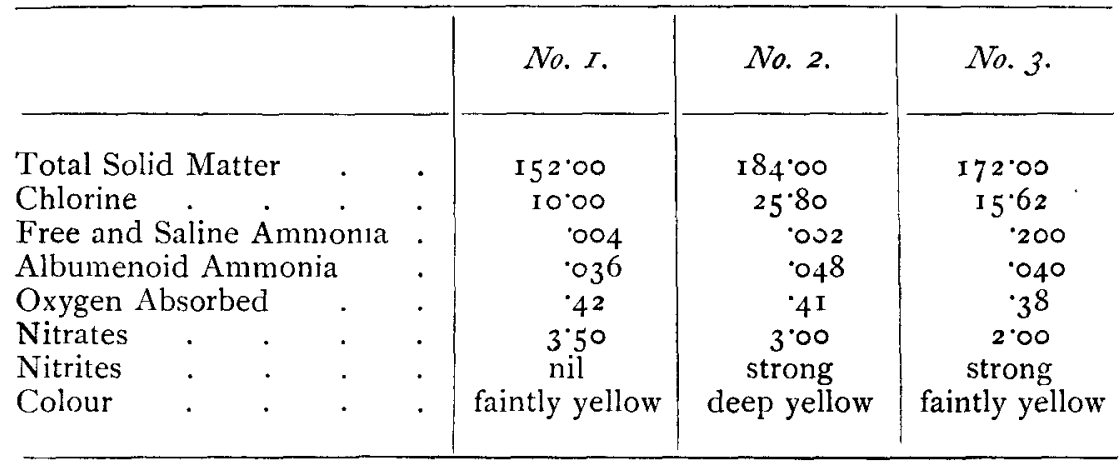

"The above are typical samples of water used in this district for stable and farm-yard purposes, and are in no way specially selected for the purpose of this report. All are contaminated."

Stored Rain Water from Cisterns-Analysis of Three Samples, in Parts per 100,00o.

\begin{tabular}{|c|c|c|c|}
\hline & No. $I$. & No. 2. & No. 3 . \\
\hline Total Solid Matter & 7.00 & 400 & $28 \cdot 00$ \\
\hline Chlorine & 47 & 47 & $2 \cdot 28$ \\
\hline Free and Saline Ammonia & .070 & very faint & excessive \\
\hline Albumenoid Ammonia & .024 & traces &, \\
\hline Oxygen Absorbed . & 27 & $\cdot 13$ & 80 \\
\hline Nitrates . . & nil & nil & trace \\
\hline Nitrites & traces & nil & faint traces \\
\hline Colour . . & $\begin{array}{l}\text { very faintly } \\
\text { yellow }\end{array}$ & good & faintly yellow \\
\hline
\end{tabular}

${ }^{1}$ I have referred to these shallow wells in my notes as "soak wells."-H. C. R. 
"Of the above waters Nos. I and 3 may be classed as contaminated; No. 3 badly so, due to leaky cistern in close proximity to a cesspool. The composition of the water from the drains is of so varied a character according as the season has been wet or dry that the figures obtained by an analysis would be almost valueless. The samples of surface (shallow well) water are exceedingly hard, both of a "temporary" and "permanent" nature. In several cases these shallow well waters have been found to contain bacilli of the coli group; generally, however, except that the amount of chlorine is high, their composition is similar to other waters of this class, and, from a chemical point of view, I am of opinion that there is no reason to assume that colic would be caused by the drinking water, contaminated though it usually is, which is used in the farmyards of South Lincolnshire."

These remarks and analyses of $\mathrm{Mr}$ Bell are quite sufficient to point out that we must look farther than the water itself as a cause of colic. We must fall back entirely on its mode of administration; I have already referred to it under the heading of Food, and will mention it again in the next section.

Errors in Proper Distribution of Work, Rest, Watering, and Feeding.- Whether the horse be in hard, every-day work, or out of harness altogether, he has at the customary hours the same quantity of food thrown into his manger. These hours, by the bye, are only twice daily-one large long feed at daybreak and another large feed towards evening. Then, again, in Lincolnshire, there is often one long spell of work from seven o'clock in the morning until three in the afternoon, during which time no break is made to refresh the animals; no water to drink; no nose-bag to their faces. A break they certainly get at eleven o'clock, when they stand in a profuse perspiration still harnessed to the harrow or the plough in the middle of a field; their heads down, and a biting, cutting, cold east wind, from which in the Fens there is not a particle of shelter, blowing about them while the man in charge, under lee of a close cut hedge, sits stolidly munching his lunch. Again, without bite or sup, they resume their work and remain at it until three. Then, in a state of exhaustion and fatigue, when the powers of the digestive tract are probably at their lowest, the animal is placed in front of an enormous feed of indigestible bulky food. After filling his stomach to the full, he is then allowed to fill himself well nigh to bursting point with the water he has perhaps been craving for all day. Every practitioner in this district must well know the Monday evening crop of colic. Sunday's rest, Sunday's gorging, and Monday's day of ceaseless work and fasting, all combine to produce the colic of Monday evening.

This is the state of things existing in the winter months, with perhaps the break in field operations occasioned by a spell of frost, which again only means another period of gorging in the stables. In the summer months the animals live the greater part of the time in the open, and the veterinary surgeon's sphere of usefulness is over at least for a time, with one exception. It is no uncommon thing for a farmer to take his nag straight away from pasture, give him a feed of corn, and drive him full of grass, long-coated, ungroomed, and perspiring, six, eight, or ten miles to the nearest market town. Here 
he is allowed to stand huddled up with several of his fellows in a dirty and badly ventilated stable, from 8,9 , or Io o'clock in the morning until 3,4 , or 5 in the afternoon, during which time he has not eaten or drunk a mouthful. He is then geared to the cart again, and does the return journey. His reward for that on reaching home is an extra large feed of corn, given at a time when I unhesitatingly say he should have less; after which he is again turned out into the field for the night, to stand, perchance, the whole of the time in a pouring rain.

The Influence of the Time of Day on the Production of Colic.-As far as I remember, Veterinary-Major F. Smith was the first to point out the enormous number of colic cases that occurred after the hour of 2.30 P.M., as compared with those occurring earlier in the day. Following Major Smith's example, I have tabulated my cases, and the table beneath will show that the majority of cases in this district are attacked between the hours of 12 noon and 7 P.M. inclusive.

\begin{tabular}{|c|c|c|c|c|c|c|}
\hline \multicolumn{2}{|c|}{ Hour. } & Cases. & Hour. & Cases. & Hour. & Cases. \\
\hline & A.M. & o & I 2 (noon) & 3 & 8 P.M. & $\circ$ \\
\hline & ," & I & I P.M. & 0 & & 0 \\
\hline & " & 2 & 2, & 0 & 10 & 0 \\
\hline 7 & $"$ & I & 3, & 2 & 1 I,$\ldots$ & 0 \\
\hline 8 & ., & $\circ$ & 4, & 3 & I 2 (midnight) & 0 \\
\hline 9 & ", & 0 & $5 "$ & 0 & I A.M. & 0 \\
\hline IO & ", & 0 & , & 2 & $2 "$ & $\circ$ \\
\hline I I & , & 2 & , & 2 & 3 & \\
\hline
\end{tabular}

I am decidedly of the opinion that in this district the long stretch of work without food, and again the ravenous feeding on bulky indigestible material immediately afterwards, are the direct cause of the attack. Also I have noticed that invariably the cases which turn out to be fatal are those occurring in the early hours of the morning; say from 4 or 5 A.M., and between that and noon.

Other Causes of Colic, Particularly Obstructive.--Ingestion of food contaminated with sand or gravelly material, or containing materials (scraps of iron, wire nails, etc.) likely to form nuclei of calculi. Catarrh of the intestines often accompanies influenza and many respiratory affections, and animals convalescent from these maladies have a weakened digestive tube and are prone to constipation and impaction. Aneurisms of the anterior mesenteric artery, due to the presence of strongyles, frequently determine impaction of fæces, owing to the interference with the blood supply to the cæcum and colon. Detached pieces of the thrombus attending the aneurism break off and effectually plug smaller arteries supplying mainly parts of the crecum and colon. In the anæmic area of the bowel thus produced peristalsis is diminished, or perhaps altogether in abeyance. As a consequence we get great weakness, or even paralysis of the bowel, with a tendency to stasis of its contents, and obstruction from fæcal accumulations. Other factors that directly or indirectly tend to induce constipation and fæcal obstruction are-large quantities of omental fat, pressure of tumours, and repeated pregnancies, distending and weakening the abdominal parietes. For my own part, I am quite satisfied that the mere presence of the fotus in the latter 
stages of gestation is mechanically accountable for many of our cases of obstruction. Occupying as it does a large proportion of the abdominal cavity, it must interfere largely with the actions and movements of the intestines. That is leaving out of the question entirely the fact that a diversion of a large blood current, at the expense of the mother, is necessary for its development.

\section{SYMPTOMS AND DIAGNOSIS.}

With acute intestinal obstruction 1 am not dealing, but may just mention that under the heading will come partial or complete twist of the bowels, etc. The character of the pain is generally acute and agonisingly persistent, and the disease runs a rapid and fatal course of from twelve to twenty-four hours. I have noticed this disease here, as it will be absolutely necessary for us to negative the idea of our case being of the acute description before a suitable and proper treatment can be adopted. I do not imagine for one moment that this conclusion may be arrived at by a hasty and half-hearted examination of our patient; for, as a perusal of the table of cases at the end of this article will show, we may be deceived by the symptoms, the pulse, the temperature, or the respirations; or we may be misled by all combined, if our examination be not a lengthy and a searching one.

Dull Subjective Symptoms.-The symptoms of a sub-acute attack will be in the main what are nearly always, and I think correctly, described by practitioners as "dull pains." They are of so plainly a dull character as to lead the owner to treat the case lightly and to neglect sending for assistance at the first onset. Frequently he allows twelve or even twenty-four hours to elapse before sending for skilled advice. The animal is dull and listless; perhaps refuses his food, or picks a little now and again. At this stage the pulse, temperature, and respirations are but little altered; these, however, change as time goes on, and the animal begins to show signs of uneasiness and pain, such as walking round the box and smelling at the bedding. Otherwise, he leans heavily with his hind quarters against the nearest post or wall, with an occasional pawing movement of the fore limbs, or an irritant stamp of the hind. Perhaps the animal even ventures to lie down, and, if so, only after repeated and careful crouching movements.' As he stretches himself out he emits a long drawn sigh, or a slight but lengthy groan, and then lies out at full length, for it may be an hour at a time. While down, his pain is manifested by his occasionally bringing the head round to the side, and looking with anxious and troubled countenance towards his flank. Also the breath is held after the act of inspiration, and retained until the voluntary muscle is overcome by the deoxgyenated state of the blood in the vessels of the brain. After lying for some time, he will get up and exhibit the same set of symptoms again from beginning to end.

Dull Objective Symptoms.-Examination per rectum will generally show that bowel to be empty, or containing at the most a few small, hard, and mucus-covered frecal lumps. The bowel is sometimes, though not always, what is termed "ballooned," and we may, or may not, notice violent straining attempts on the part of the animal at 
defæcation. It may be, however, in some cases, that the rectum is not empty, but full to a state of impaction, with material varying from a semi-fluid to a solid consistence. The bladder is usually empty, and nearly always other portions of the intestines can be felt crammed to their full with impacted fæcal matter. Auscultation of the abdominal walls reveals not the slightest sign of peristalsis. Sometimes there is an accompanying slight tympany, and during auscultation we may then hear a peculiar metallic tinkle, caused by some slight attempt of the bowel at peristalsis. Contrary to many, I attach no grave importance to that sound; rather the reverse. The extremities are cold, and the mouth clammy and foetid. When hereafter I allude to "dull" pains, I am referring to the symptoms described above. Often, however, we may have symptoms much more violent and alarming.

Acute Subjective and Objective Symptoms in Sub-Acute Colic.-The pain becomes much more violent. The animal walks round and round his box. The ears and extremities become deathly cold. Cold, patchy, perspirations bedew the underneath surface of the abdomen, and break out between the forearms and the thighs, while the expression becomes anxious to an alarming degree. Tympany becomes much more noticeable; the animal reels in his walk, and casts himself down with such violence as to almost resemble a fall. The pulse is now increased in frequency, and is not so full to the fingers. The mucous membrane (conjunctiva) becomes injected, and appears of a deep red hue. Frequently, too, in this special form of colic the membrane is tinged with yellow, reminding one of the early stages of jaundice.

At this stage, too, I cannot lay too great a stress on the value of taking the indications of the pulse, temperature, and respirations collectively, in order to avoid error in prognosis. I never look upon a case as approaching dangerous unless I get a full warning from all three. A reference to Case No. 7 will explain what I mean. Here was an animal which had been rolling in violent pain before my arrival, but was now standing perfectly quiet. An alarming state of the pulse was evident, hammering away at the rate of $108^{\circ}$ to the minute. The temperature, however, was only $101^{\circ} \mathrm{F}$, and the number of respirations 12 . The animal recovered.

Take again Case No. 6. The respirations here were a continual sob of 32 to the minute, and the horse in a bath of perspiration for over an hour. The pulse was only 48 , and the temperature $104^{\circ}$. The animal recovered.

Or take Case No. 3. The temperature, $96 \cdot 6^{\circ}$ (which may be taken as sub-normal in shire horses) was counter-balanced by the pulse (48) and the respirations (13). This animal also, after a lengthy illness, recovered.

Here I may state that I believe it to be absolutely impossible to diagnose "straight-away" even this, the most easily diagnosed and best understood of all our cases of colic. What I mean is that no committing statement ought to be made, and no large amount of drugs exhibited, until the case has been closely watched for some considerable time, e.g., witness Case No. I3. Judging from my foregoing statements, the irregularity of the respirations and temperature in this case certainly should have warranted a bad prognosis. Still, 
we had a perfectly normal pulse-normal, in number, tone, and frequency. Nevertheless, at the expiration of an hour I gave a fatal prognosis, and the animal died nine hours later. The pulse began to increase in number, and decrease in tone.

I have purposely described symptoms and diagnosis in one paragraph because I do not believe in such a thing as a diagnostic symptom. It is only by a complete and orderly analysis of the whole of the history, and by a proper weighing of all the signs, that a correct diagnosis may be arrived at. Nevertheless, I am fully persuaded that this is the most easily diagnosed of all our cases of colic; and concerning it a mistake ought seldom or never to be made.

\section{TREATMENT.}

I used to think at one time that, having properly and correctly diagnosed a disease, its treatment would necessarily follow naturally. A long plodding through the annals and records of veterinary medicine has shown me, however, that such is not the case with this particular disorder. In no single disease, I imagine, have so many and widely different drugs been given. From the most potent sedative the pharmacopoia possesses to the most violently powerful and drastic purges the world produces - they have all been given. Not only have they been given, but they have been indiscriminately mixed in single cases. I do not believe in giving purgatives and stimulants with one hand and sedatives with the other. Above all things, whether the occasion demands the exhibition of aloes, or the injection of morphia and atropine, let us abide by the one treatment we have decided the case merits. We all know that the men of the medical profession have for the treatment of a certain form of colic one sheet anchor; that is castor oil and opium. They one and all uphold it, but there have yet to be found two veterinary surgeons who treat a case of obstructive colic on identical lines. There must be one right way, and only one. That way I endeavour to point out in this section of my paper.

To commence with, provided we have diagnosed our case, and are certain that we have purely a case of sub-acute obstructive intestinal colic to deal with, we cannot do better than ask ourselves the following questions:-

I. What is the exciting cause of the attack?

2. What is the cause of the pain?

3. What is the actual condition we are called upon to treat?

4. What part of the animal system is it best to operate through? The digestive, or the nervous? Or should our attack be directed mainly upon the offending structure itself?

I. What is the Exciting Cause of the Attack? - To that question I answer, undoubtedly in 99 cases out of 100 it is the nature, bulk, or mode of administration of the animal's food. Whether of an indigestible nature, whether given in too large a quantity, or whether given in such a manner and at such a time as not to admit of a free action upon it by the gastric and intestinal fluids, the result remains the same, viz, impaction of a certain portion or portions of the alimentary tract with a mass of improperly digested food. 
2. What is the Cause of the Pain?-The pain, I think we may safely answer, is brought about by active peristalsis, followed by, spasm of the bowel, either on both sides of, or before, or behind the point of obstruction. This pain, of the severity of which we may judge by noting the animal's symptoms in the most acute cases of obstruction we have, viz., twist, we may designate as cramp. This explanation of "cramp," however, does not altogether meet the case when we are talking of obstructive colic in its sub-acute form. Here, in the majority of cascs, we have a state of impaction from end to end of the alimentary tube. What, then, will be the cause of pain now? It may be, and is partly, due to pressure on and consequent irritation of the delicate nerve endings in the bowels themselves. When, however, we consider that the bowels, already crammed to their full with half digested matter, are sometimes further distended by the evolution of gases from the frcal masses, we may confidently assert that we have another and totally different condition of the bowels to reckon with. I am alluding to "tonic spasm." When a muscle, or its motor nerve, receives an abnormal number of vibrations or is over-stimulated, instead of contraction being followed by relaxation, permanent contraction or tetanus ensues. The bowels distended beyond a certain point are retained in a state of tonic cramp in their ineffectual attempts to deal with the enormous masses they contain. That this is so is fully proved by the entire cessation of peristalsis in many of our cases, as witnessed by auscultation. Call it tonic spasm, cramp, atony, paralysis of the bowel, or what we will, it still remains that we have a torpid and stationary condition of the bowels to treat. It is this state of tonic spasm of the whole of the intestinal tract that has, in my opinion, been so generally overlooked in the treatment of veterinary obstructive colic.

3. What is the Actual Condition we are called upon to Treat? - The favourite but evasive reply of the practitioner of veterinary medicine to that question is "remove the cause, and the effects or actual condition will cease," and, accordingly, in every case he gives a dose of physic. That physic is invariably aloes. I maintain, however, that before we proceed in an attempt to empty the bowels by such a mechanical method as the administration of aloes, we ought rather to stay and ask ourselves- "Can we, by any other means, put the tetanised wall into a state approaching its normal condition, and so enable it itself to deal with the offending obstruction?" I think we car, and reserving my reasons for so saying, will conclude my remarks on this question by stating that, in my opinion, it is the tonic spasmodic seizure of the bowel itself which is the actual condition we are called upon to treat in obstructive colic.

4. What Part of the Animal System is it best to Operate through? The Digestive or the Nervous? Or should our Attack be directed mainly against the Offending Obstmetion Itself? - The whole crux of the argument concerning the treatment of colic lies in the answer to this question. For my own part, I believe that the treatment of the nervous division of this ailment should receive our almost undivided attention, and I further believe that the administration only of drugs that act wholly or mainly on the digestive tube itself, and not on its nervous supply, are unproductive of good, if not altogether harmful. Remember, we cannot depend on the physiological action of the drug 
being sure to ensue in this case. We are putting our drug into contact with a diseased organ, and must not expect that organ to take up, assimilate, and respond to that drug as the same organ would do in health. The disease of the organ in this case is its atony, spasm, or paralysis. Relieve that, and the bowels will relieve their impaction themselves. Intestinal movements are dependent on the ganglia of Auerbach's plexus, situated between the longitudinal and inner circular layers of muscle. Secretion is believed to be influenced by Meissner's plexus, lying in the sub-mucous coat. Both these ganglia, however, are controlled by cerebro-spinal centres and nerves, notably the vagi and the splanchnics. Here, then is pointed out a ready and open road to a correct treatment, and one which may be followed without the aid of one purgative dose of medicine. Give a large enough dose of a cerebro-spinal stimulant, and, theoretically, the case should at once begin to mend. Practice in this case, I can confidently state from experience, only bears the theory out. To make my standpoint clear. I must analyse a few of the actions of the more important drugs used in every-day practice in the treatment of this disorder. As the main object of this paper is to direct attention to what the writer believes to be the dangerous practice of giving aloes, and to the greater success following a nervous stimulant treatment, I must confine myself to the drugs under those headings, concluding with a brief paragraph on the use of anodynes and sedatives.

\section{ALOES.}

Reasons advanced in Favour of its Administration.-It causes a purge not only of the bowels but also of the blood. While in contact with the intestine it produces secretion and peristalsis. It also increases the flow of bile.

Reasons why it should not be Usell:-

I. The length of time it takes to act (sixteen to twenty-four hours) is much too long to have to wait in the horse for an action of the borvels. That must be evident to everyone in view of the time occupied in the passage of food through the digestive organs.

2. We are waiting then for a something only problematical, for oftentimes it never acts at all, but is excreted wholly by the kidneys, causing hyperæmia of those organs and diuresis.

3. The drug is always more or less nauseating.

4. Its effects are confined mainly to the large intestine; consequently, if atony of the small intestine exists, it may never reach the position in which its action will be most marked.

5. It needs to be saponified and emulsified by bile before its prompt solution can be counted on.

These last two reasons may be considered a little more in detail. It is they that have already made me refer to the action of aloes as "mechanical." No one will dispute in face of statements number 4 and 5 that two purely mechanical processes have to be gone through before we can confidently calculate on a dose of aloes creating a purge. It has to pass almost passively through the small intestines before it can reach the large, and it requires also to be mixed mechanically with bile before its solution can be expected. Unfortunately, in subacute obstructive colic these very two processes that are necessary 
for the prompt action of aloes are not at all likely to come about. Regarding the first process, I have already pointed out that there is in this form of colic very little movement of the bowels ; consequently, the drug may remain almost stationary in the stomach, or at the most gain the first few feet of the small intestines.

With regard to the second process comment is well nigh useless. In sub-acute obstructive colic there very frequently is considerable jaundice and torpidity of the liver, and in that case the aloes cannot act, or, at the least, its action is most certainly delayed, owing to the fact that the bile necessary for its prompt emulsification and solution is deficient, or altogether wanting.

6. Finally, in the horse there is always a danger of super-purgation, followed by enteritis, laminitis, or possibly death. This ought never to be overlooked.

I am sure that every practitioner who has been in the habit of exhibiting aloes in this disorder must have sometimes been greviously disappointed and mortified. Disappointed and annoyed to see his case recover from the disease he has been treating it for, only to turn round and die in a few short hours, as a result of the treatment itself. Truly, that treatment was worse than the disease. I say here that, if there is a possibility of that occurring in only I per cent. of our cases, then aloes ought never to be used. As a matter of fact, when aloes is regularly given it happens very much more often than that.

\section{AMMONIA.}

Although there are many more to choose from, the drugs I have used as stimulants, and more particularly as nervous stimulants, have been ammonia and nux vomica.

For ammonia, and especially the carbonate, I have a particularly strong penchant. That I am not the only one so inclined I can show by a few remarks extracted from an article on "Ammonia and the Stimulative System of Treatment in Disease." This was written by the late Principal Walley in I879; but, I may add, I had arrived at almost similar conclusions before reading his opinions. He says :"Physiologically, ammonia acts as a powerful stimulant, but does not like alcohol increase mental activity, nor does it to the same extent increase the force of the circulation. Its action as a stimulant-owing to its being quickly excreted-is as fugitive as it is rapid, but it does not produce much secondary depression ... . It is, too, a powerful stimulant to all the glands of the body, as well as to the mucous surfaces generally, acting upon the mucous membrane of the alimentary tract, upon the kidneys, the skin, and the liver. Its effects as a general gland stimulant are well seen in those cases where the pulse is firm, the skin dry, the kidneys inactive, the mucous membrane icteric, the bowels sluggish, and the fæces coated with mucus, with a hot, dry, and furred condition of the mouth. ${ }^{1}$ A few doses of ammonia here will, by stimulating gland function, rapidly alter these conditions. In the stomach and intestines ammonia acts as an antacid and antitympanitic. It is useful in acute or sub-acute indigestion in horses and cattle when purgatives have failed to act, and the animal shows signs of exhaustion, alternated with strychnine and nux vomica. In

\footnotetext{
1 All symptoms of sub-acute obstructive colic-H. C. R.
} 
the early stages of tympany, the liquor or the carbonate unite with the liberated carbonic acid, and fix it, and in any stage are beneficial by stimulating the mucous membrane to increased activity, by rousing nervous energy, and by assisting and preventing decomposition."

Like Professor Walley, I can speak from experience as to the beneficial actions of this drug in sub-acute indigestion, and I prefer the carbonate for these reasons: it is less volatile and rather more permanent in its actions than the hydrate; also, it is more easy of administration, as it may conveniently be given in the form of a bolus.

\section{NUX VOMICA.}

I consider the use of this drug to be specially indicated in the treatment of sub-acute obstructive colic. It is a gastric, vascular, and nervous tonic, and anti-paralysant; and, as I have before pointed out, seeing that the condition which we are to treat in this disorder is mainly one of nervous atony and spasm of the bowel, it must be apparent to every one that none but the most favourable results will follow its administration. I must not finish my remarks on this drug, however, without a brief reference to two articles in the Journal of Comparative Pathology and Therapeutics (Vol. V.). Two cases are reported there of salivation caused by the administration of nux vomica in $3 \mathrm{i}$ and $3 \mathrm{ii}$ doses respectively. The dose I am advocating exceeds this by six or seven drachms, and I can confidently assert that in no single case have I noticed anything of a similar nature. It must be remembered, however, that in the majority of my cases I was dealing with large, full-grown, gross agricultural animals; and that their systems were in a state calling loudly for some active and powerful stimulant.

\section{TURPENTINE.}

It will be seen, on referring to my report of cases, that in many instances I have used oil of turpentine, combined with linseed oil. I have used that drug on account of its antiseptic and stimulant actions. I have given it mainly to satisfy local prejudice, which thinks that no medicine can be a medicine unless in the form of a drench, and have chosen it particularly as conforming closely to the lines on which my treatment is based, viz., stimulative.

\section{ESERINE OR PHYSOSTIGMINE.}

Regarding the use of this preparation, I have nothing to say that is not in its favour. I regard it as the most valuable of all recent additions to veterinary medicines. Should we give it to pregnant animals? In Vol. II. of the Veterinary Record, Horner describes two cases of mares in advanced pregnancy receiving one-tenth of a gramme of eserine and aborting soon afterwards. That should be sufficient to point out that its use must be tempered with caution. Only after all other means have failed, and it becomes not only a question of the life of the toal but also that of the mother, should it be given. For my own part, I have given it to in-foal mares repeatedly, and have not met with an untoward result yet. With this one exception, I firmly believe that it may be administered advantageously in every case of sub-acute obstructive colic. To those who complain of its 
action being uncertain and unreliable, I would reply in the words of one of our greatest veterinary writers, "Give a dose sufficiently large, and you will not be disappointed." It will, when all our other efforts have proved futile, restart that peristalsis which means life to our patient, and the cessation of which means death. I do not, however, believe a full dose to be always necessary, and have seen doses of one grain do all that the most fastidious would require. That dose is sufficient to incite the bowels to action in most cases, and that without an exhausting and painful evacuation of large volumes of frecs. If that dose fails, it may safely be repeated later in an increased quantity, say two grains, beyond which it is not wise to push its administration.

\section{SURGICAL TREATMENT OF OBSTRUCTIVE COLIC.}

Puncturing the Abdomen.-I hold this operation to be advisable: $(a)$ in every case where any large amount of flatulence occurs ; $(b)$ in every position where the flatulence is most prominent. I do not consider it in any way dangerous, and have never had a single bad result follow its performance. It is the one direct means at our disposal of immediately relieving the distension of the bowel ; and in so doing we, in many cases, favourably influence peristalsis. The relief obtained by the patient, and the after good results, are matters of everyday observation, and there is no need for me to enlarge upon that here. Always have the trocar scrupulously, antiseptically clean; and always have one that is not deficient in length. It should be six inches or longer.

The Performance of Laparotomy for the removal of the obstruction does not properly come within the scope of this paper. It is more a matter of consideration for the surgeon than the physician. That it may be done, and done successfully, too, is fully pointed out by Professor Macqueen, F.R.C.V.S., in a paper on Abdominal Surgery, discussed before the National Veterinary Association in 1895 . The surgeon here has contributed his quota to the knowledge required, and it only remains for the physician to diagnose and bring forward suitable cases for operation for it to become a real and useful acquisition to veterinary knowledge. This much is certain; the indiscriminate performance of this operation on unsuitable cases, and patients in the last stages of collapse, will only serve to bring it into disrepute, and will not, in common parlance, "give the operation a chance." Personally, I am afraid that until the different branches of veterinary science have become more distinct, and specialists have begun to crop up in our midst, our powers of diagnosis will remain too limited to allow of correct cases being pointed out for operation.

\section{SEDATIVES.}

Our choice of these is a large one, but before saying more I would ask, "Should we give sedatives at all in obstructive colic?" Personally, I think we should not. I know that in saying so I am directly opposed to a very large number of practitioners; but still, after the experience of a large number of cases, such is my conviction. In the horse I am convinced that we have a type of colic to deal with that can in no way whatever be compared with the same disorder in the 
human subject. I claim that in no material way are the cases analogous; and nothing gives me greater annoyance when reading the report of a case than to find that the veterinary writer tries in conclusion to bolster up his treatment, theories, and arguments with extracts from books on human medicine. As a profession, we are undoubtedly largely indebted to the medical for much kind help afforded us'in the first tottering steps of our babyhood. Now, however, we can and must stand alone, and we have here a subject that needs a distinct and totally different line of thought from what the medical profession can supply us with concerning the same disorder in their patient, in order to enable us properly to grapple with it in ours. There is still room for special research of the most painstaking order. What is wanted is a long array of consecutive cases, with notes and remarks taken on the spot, and not afterwards altered and cnlarged in order to fit in with some preconceived idea. In the tabulation of cases, points invariably strike one that would otherwise be missed-points of value and interest that only a method like that can show up.

Think for a moment, that immediately we give a sedative, especially if that sedative be opium, peristalsis is hindered, if not stopped altogether, for a while. Think again, that cessation of peristalsis, if only of a few hours' duration, is to the horse a very grave and serious matter. It is no use blinding ourselves with the idea that if aloes has previously been given we may safely lull the pain while the aloes continues to act. Remember that "lulling the pain" to a very large extent means also "lulling the physic," and that lulling the bowels in the horse with physic means lulling him to death. Perhaps, and it may be most likely, the type of colic I have largely to deal with in this district has had a great deal to do with my arriving at this conclusion. To those who must and will use a sedative in colic, let me recommend to them the use of chloral hydrate in one ounce doses in preference to opium. It is antiseptic in its action, there are not the after bad constipating effects of opium, there is not that mad delirium, and there is not the amount of dangerous tympany that opium invariably calls up. It is safe to use, its action is soon apparent (usually well within ten minutes); and if its effects are somewhat transient, why, then, the same dose may safely be repeated after a short space of time. It is not followed with nausea, and, compared with opium, it does not interfere with the peristaltic movements, and does not hinder intestinal secretions. Here, again, I have notes of a case in front of me where the veterinary writer states that medical men "pooh-pooh" the idea of chloral being of any use in these cases. Well, let them do so. They are not in the habit of prescribing for the horse, they are not acquainted with his internal anatomy, and they are certainly not largely experienced in the action of drugs upon him. That chloral is not an anodyne in the strict sense of the word I know. I know that it does not act as a sedative to the periphery of sensory nerves. It acts, however, in an indirect manner through the nerve centres, and almost invariably induces sleep. Compare the stretchedout, comfortable sleep of the griped animal under the influence of chloral with the mad delirium so often seen with opium, and one can no longer remain in doubt as to the superiority of the former over the latter in our favourite subject, the horse. 
Here are a few of Mr Hunting's remarks re the use of sedatives in colic, and with them I must close. He says :- "It was argued that in the human subject they administered sedatives with the intention of alleviating the pain, and when they had once stopped the spasm there was no fear of impaction. After the spasm was got rid of, that then the normal condition of the bowels would be resumed, and the indigestion pass away. Personally, he ( $\mathrm{Mr}$ Hunting) believed that, so far as the horse was concerned, that was arguing upside down. He held that the impacted food was the cause of the spasm or pain, and that the proper thing to do was to remove the cause, even if they inflicted a little more pain: He could say honestly and fairly that he had had a greater number of recoveries under the aperient and stimulant treatment than under the sedative treatment alone."

I myself can emphatically endorse all that Mr Hunting says there. I have observed exactly the same results follow the disuse of sedatives; and I guarantee that the number of Mr Hunting's successful cases would go up with a further bound if he also discontinued the use of aloes.

\section{POSOLOGY.}

Before leaving the question of treatment, I think it advisable to mention the quantities given of the drugs advocated. Provided the animal is suffering from a bad attack of the disorder under consideration, with all the symptoms well marked, and the least possible chance of error in diagnosis, I exhibit the following :-

R. Ammon. Carb. Pulv. . . . 亏̈ii.

Nucis Vom. Pulv. . . . . Z zi.

Sapo Mollis q.s. ut fiat bol.

Misce, fiat bol iv.

Sig. The four balls to be given at once.

R. Ol tereb.

$\begin{array}{ll}\text { Spt. Ammon. Ar. a.a. } & \cdot \quad \cdot \quad \text { jii. } \\ \text { Ol. Lini ad. } & \cdot \quad \text { Oj. }\end{array}$

Ol. Lini. ad. .
Misce, fiat haust.

Sig. The drench to be given at once.

This treatment, with the exception of the nux vomica, I repeat again at the expiration of three to four, five, or six hours if the animal is still in pain. In the meantime I throw up frequent enemata of hot water, with sometimes the addition of 4 to 6 ounces of ordinary soap liniment. Should the case tend in any way to become protracted, and if the pulse is strong and not too frequent, I inject hypodermically eserine sulphate I grain. If on the next occasion of my seeing the case there has been no action of the bowels, and peristalsis is still in abeyance, I repeat the eserine in larger quantities (viz., 2 grains).

The preparation of eserine that I have found to be the most reliable is the following:-

$$
\begin{aligned}
& \begin{array}{l}
\text { Eserine Sulph. } \\
\text { Aq. Chloroformi ad. } \cdot \\
\text { Dose } x \text { to } 2 \text { drachms. }
\end{array} \\
& \begin{array}{c}
\cdot \\
\text { Gr. i. }
\end{array}
\end{aligned}
$$

At the same time I still continue the administration of ammonia carbonate, this time combined with zingib. rad. pulv. in place of nux vomica. In fact, it may be taken as a general rule that from the 
commencement of the pains until relief is obtained ammonia carbonate may be given at intervals of three hours in $I$ to 2 ounce doses.

The only modification to be made is when treating a nag or a very young cart animal. In this case the dose of nux vomica should be reduced to half an ounce.

Should the reader, on glancing through this last section, say at once, "the doses are far too large," I ask him to remember that the animals I am dealing with are of the heavy, lymphatic, agricultural type. I ask him also to bear in mind that it was the marvellous and striking results following the adoption of the treatment here laid down that first led to this paper being written. In the whole of my practice for the last two years, I have had no occasion save one to give aloes. That occasion is included in the list of cases at the end of this article, and I may say that, even then, I had cause to regret its administration. This section on Posology is the one in this paper that I ask the reader to ponder over most. If my description of the disorder is correct, there can be no doubt that the treatment is right in every detail.

I have seen no one case in which the apparently excessive doses have proved in any way harmful ; in fact, judging from a long list of cases, the exact opposite has been the result. To further set at rest the minds of those who think the doses beyond all reasonable limit, I may state here that one animal, in addition to the usual doses of nux vomica and ol. tereb., received of ammonia carbonate (I am almost afraid to mention it) considerably over I lb. of that drug. One pound in 2 ounce doses spread over a period of thirty hours; I need hardly say it was an extreme case. It is the occurrence of cases like that which has proved to me the value of the treatment, cases that under the old treatment of aloes and sedatives invariably used to die. Only a few trials will convince any unbiassed mind of the splendidly beneficial action of a solely stimulative treatment.

Although very much more might be written on the subject of Intestinal Obstructive Colic, I feel that already this paper has run to a length likely to tire the patience of my readers. If so, to them I apologise, only hoping that I have made it readable. This article was written mainly with one object, and to fix that firmly in the minds of my readers I cannot do better than repeat it here, and make it the conclusion of my remarks.

My object has been to point out what I believe to be the dangerous though common practice of administering either aloes or sedatives to the horse suffering from intestinal obstructive colic caused by impaction with food. One can always see more, feel more, and know more than one can write. It is not easy to gather up, classify, and tabulate all the facts, theories, and circumstances that lead one to a certain conclusion. It is still less easy to so arrange these facts as to carry conviction to the minds of others. If I have failed in that, I am still the gainer by what I have learned in tabulating my cases; and I shall not be discouraged in making an attempt at rendering myself better understood another time. If I have been successful, I am conscious of having performed a good work for my brother veterinarian, for the stock-owner, and for the veterinary surgeon's favourite -the horse. 


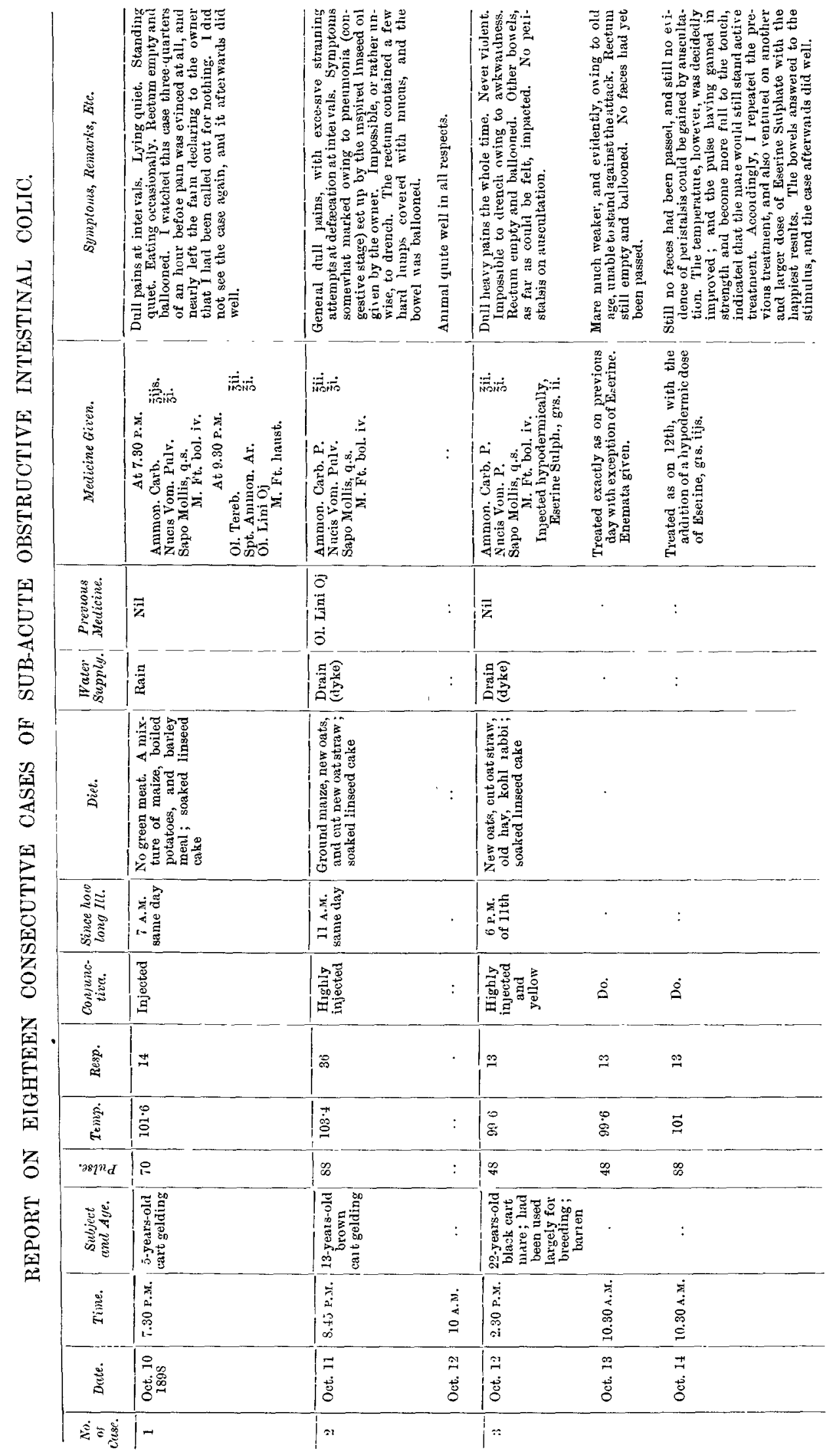




\begin{tabular}{|c|c|c|c|c|c|c|c|}
\hline 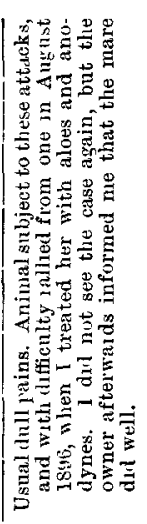 & 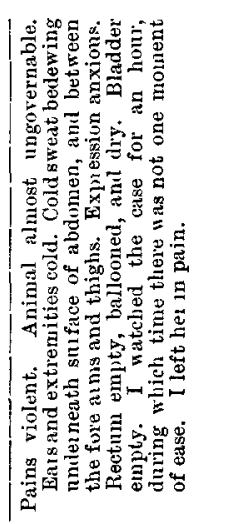 & 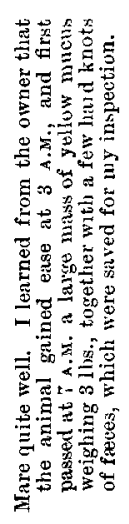 & 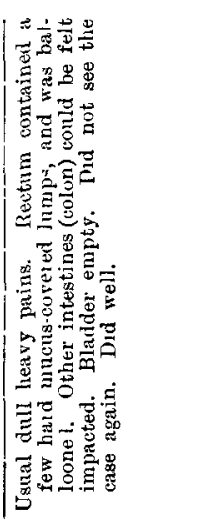 & 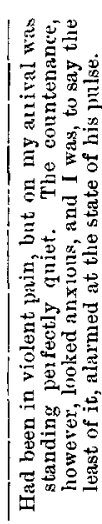 & & 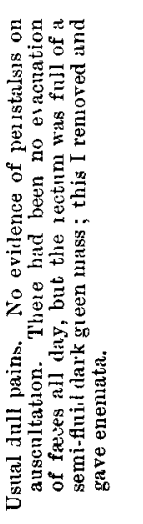 & 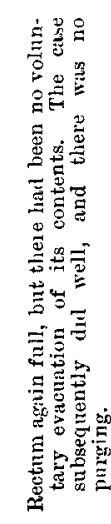 \\
\hline 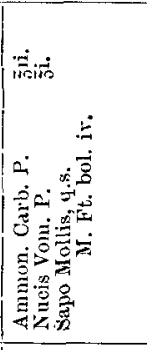 & 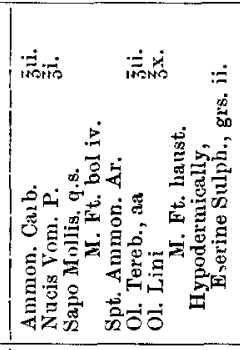 & & 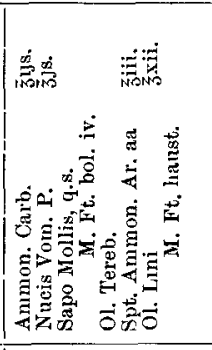 & | & & \multicolumn{2}{|c|}{ 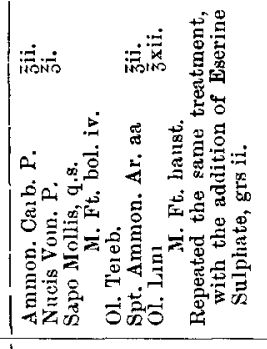 } \\
\hline $\begin{array}{l}8 \\
0 \\
\\
\end{array}$ & 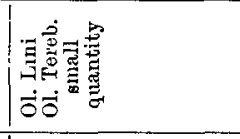 & : & 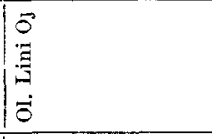 & 污 & & $\mid \begin{array}{l}0 \\
0 \\
i=9 \\
0 \\
0\end{array}$ & \\
\hline 产要 & 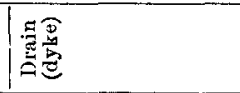 & : & 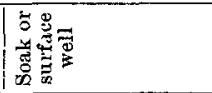 & 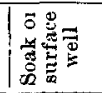 & & 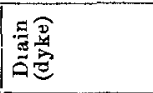 & : \\
\hline 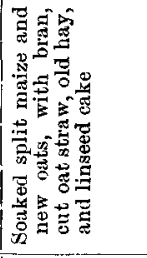 & 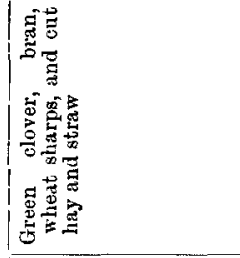 & : & 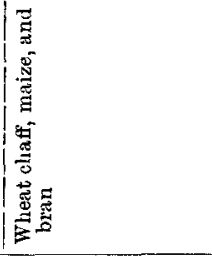 & 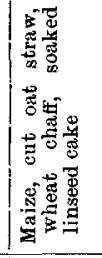 & & 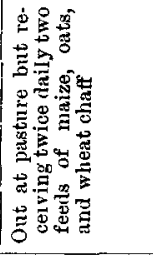 & \\
\hline 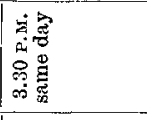 & 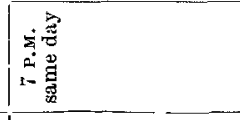 & : & 牙 & 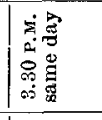 & & 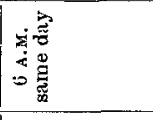 & \\
\hline 㺃 & 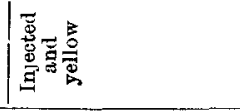 & . & 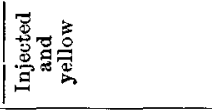 & $\mid$ & & $\mid$ & \\
\hline$\because$ & 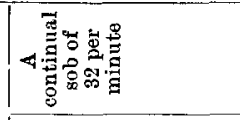 & : & $\approx$ & & & $\infty$ & $\cong$ \\
\hline 莣 & 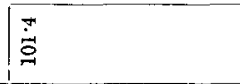 & . & $\tilde{s}$ & & & ; & $\Xi$ \\
\hline 8 & o & 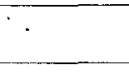 & 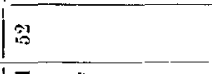 & 总 & 9 & 8 & : \\
\hline 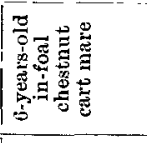 & 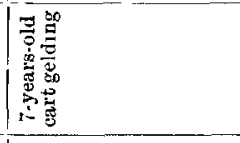 & & 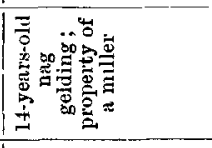 & 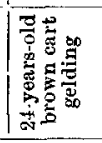 & & 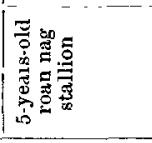 & $:$ \\
\hline 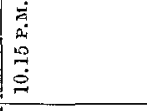 & 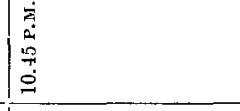 & $\begin{array}{l}\dot{\Delta} \\
\dot{i} \\
\infty\end{array}$ & 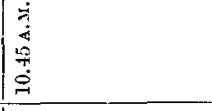 & 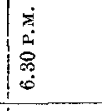 & & 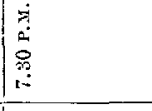 & 玄 \\
\hline \begin{tabular}{|l}
3 \\
\\
\end{tabular} & 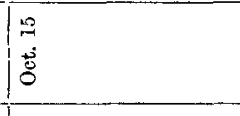 & 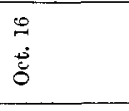 & 7 & $\mid \begin{array}{l}5 \\
15 \\
15 \\
15\end{array}$ & & 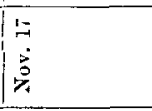 & 竞 \\
\hline$*$ & $=$ & & $=$ & in & & 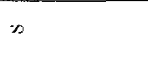 & \\
\hline
\end{tabular}




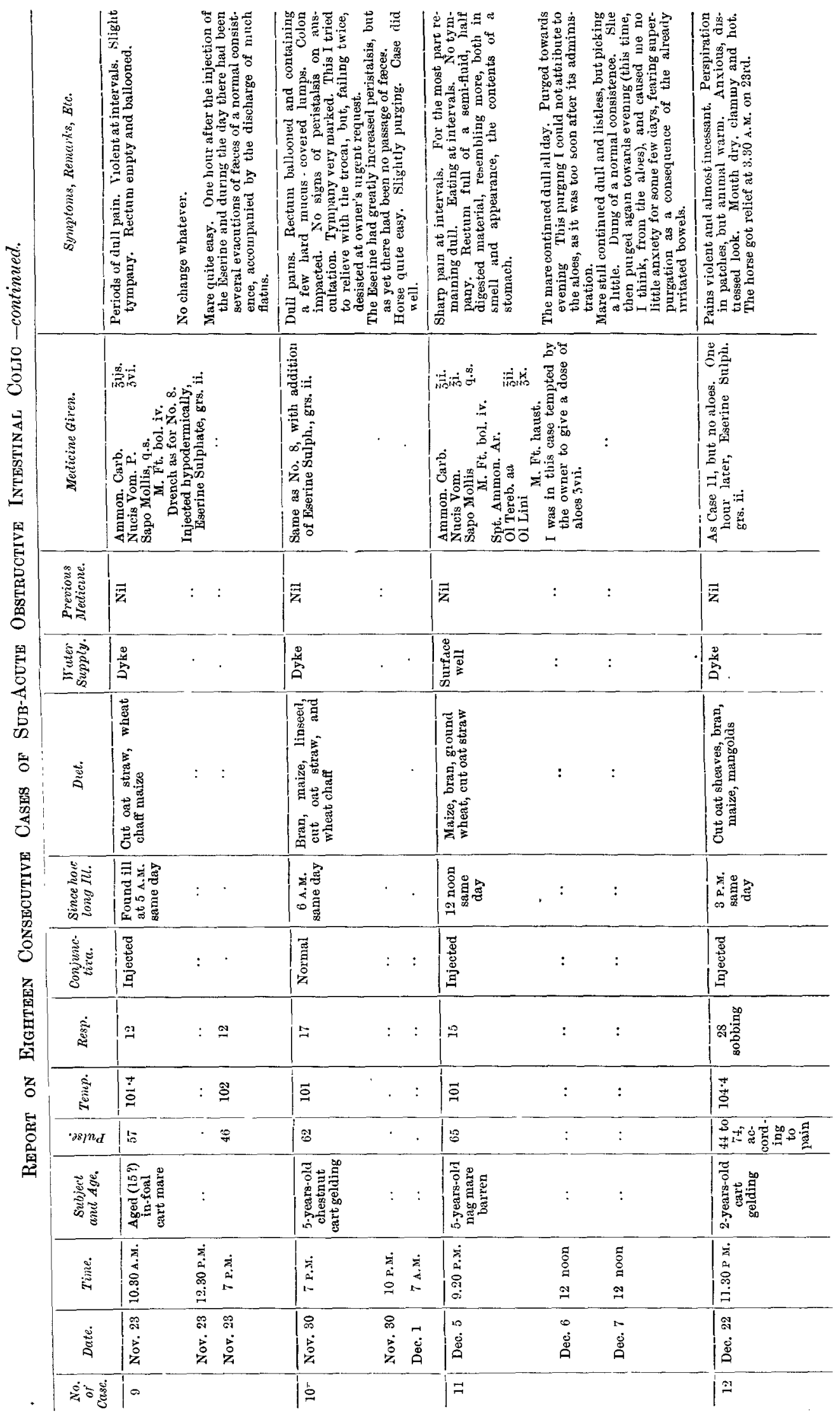




\begin{tabular}{|c|c|c|c|c|}
\hline 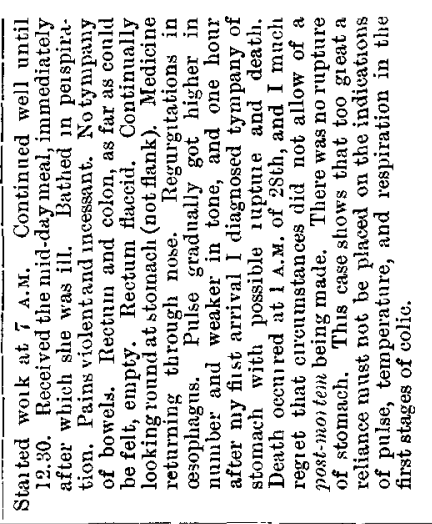 & 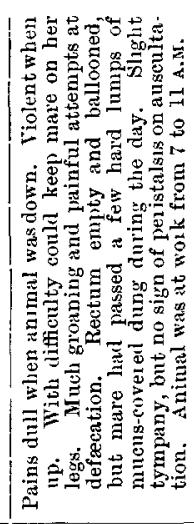 & 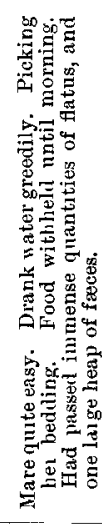 & 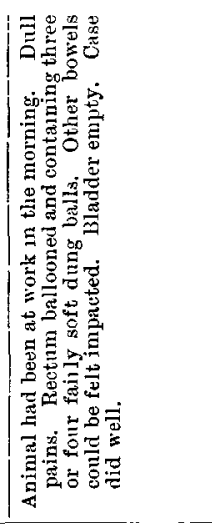 & 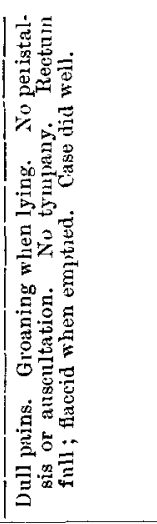 \\
\hline 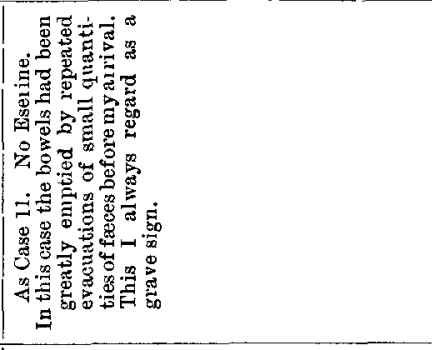 & 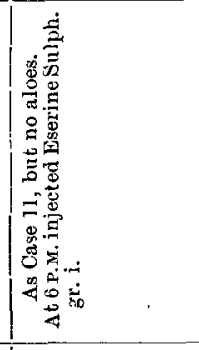 & : & 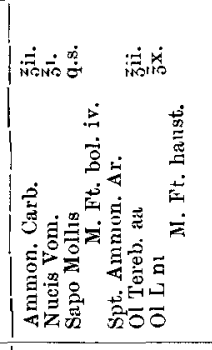 & $\mid$ \\
\hline $\begin{array}{l}\bar{\Xi}_{0} \\
\overrightarrow{0}\end{array}$ & $\overline{\mathrm{z}}$ & : & $\vec{z}$ & 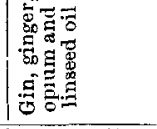 \\
\hline 善 & 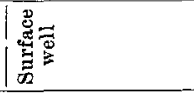 & $:$ & 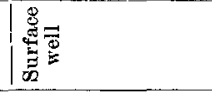 & 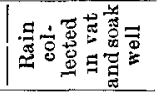 \\
\hline 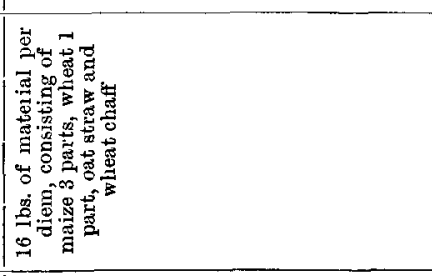 & 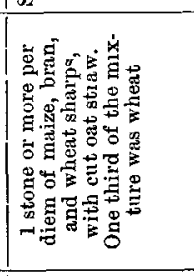 & & 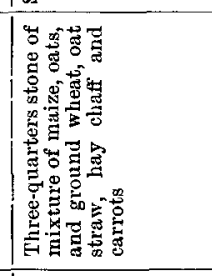 & 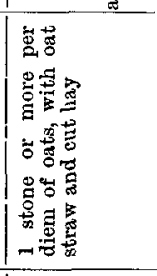 \\
\hline 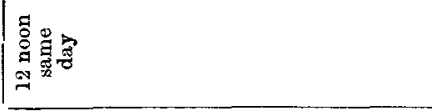 & 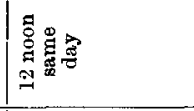 & $:$ & 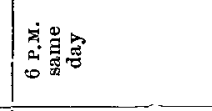 & 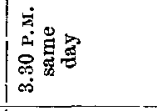 \\
\hline 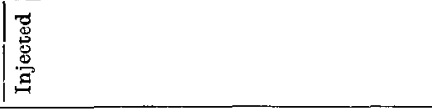 & $\mid$ & : & $\mid \frac{2}{2}$ & $\mid$ \\
\hline 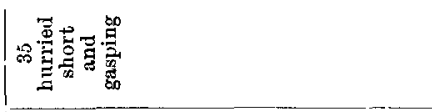 & 8 & $\cong$ & $\cong$ & $\approx$ \\
\hline 莒 & $\%$ & $\stackrel{8}{8}$ & $\$$ & 菅 \\
\hline$\ddot{*}$ & कि & क & i & $i_{0}$ \\
\hline 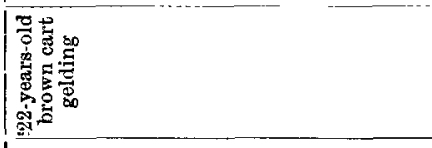 & 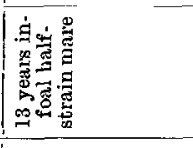 & : & 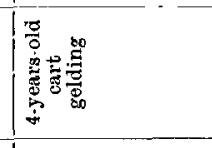 & 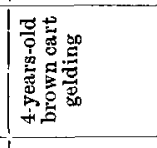 \\
\hline$\sum_{\infty}^{\infty}$ & 草 & 产 & 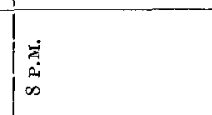 & 总 \\
\hline 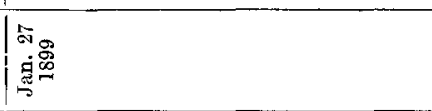 & 箁 & 它 & 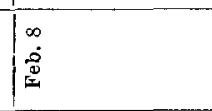 & 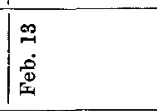 \\
\hline$m$ & 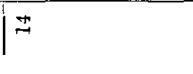 & & 19 & $1:$ \\
\hline
\end{tabular}




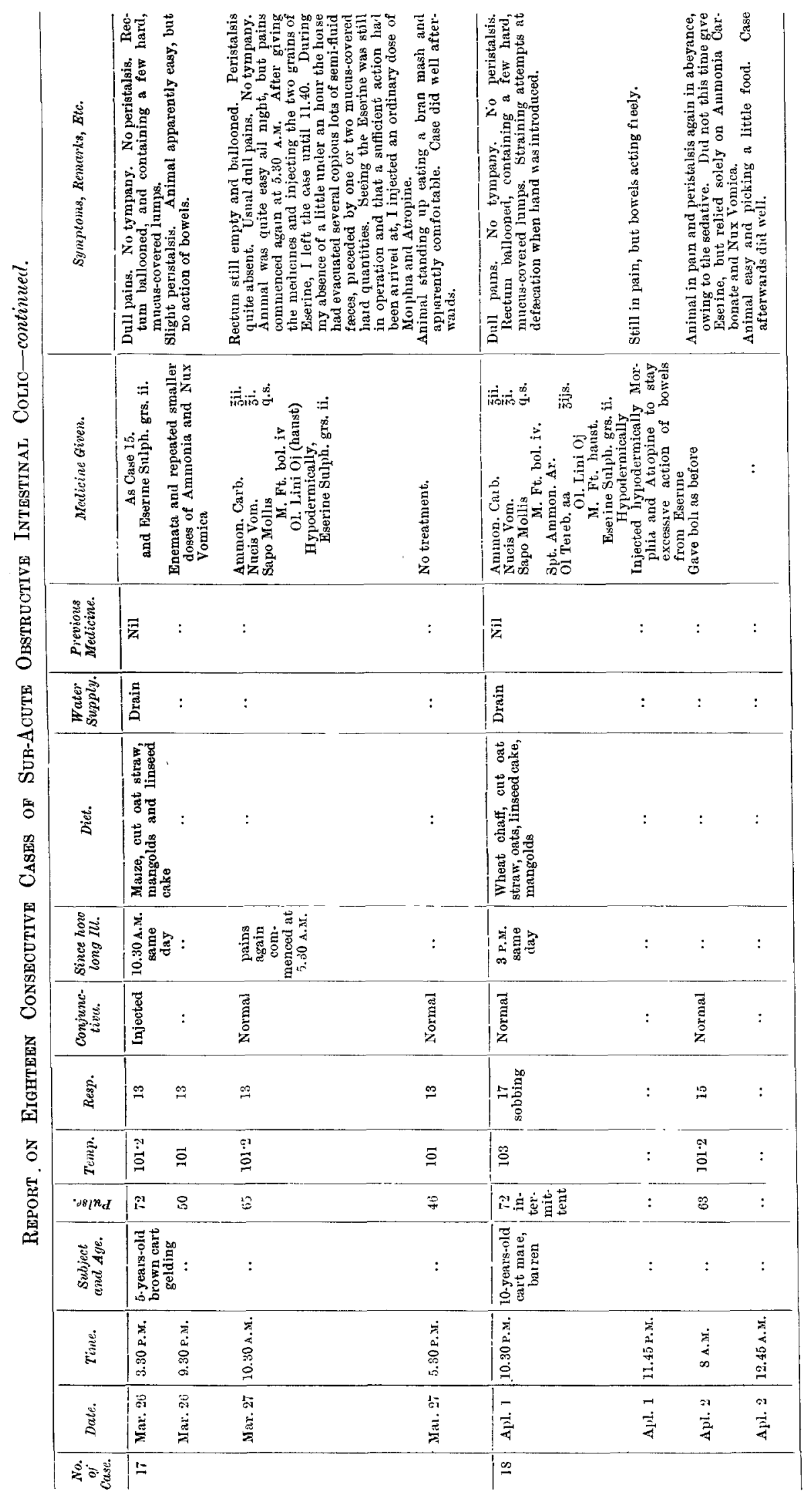

